\title{
Domestic technology developments on high-efficiency heavy oil conversion FCC catalysts' industrialization
}

\author{
Zhaoyong Liu ${ }^{1,2} \cdot$ Zhongdong Zhang $^{1,2} \cdot$ Chaohe Yang ${ }^{1} \cdot$ Xionghou Gao $^{2}$
}

Received: 16 June 2015/ Accepted: 6 August 2015/Published online: 18 August 2015

(c) The Author(s) 2015. This article is published with open access at Springerlink.com

\begin{abstract}
The article introduces industrialization status of the following products developed by Lanzhou Petrochemical Company, CNPC: olefin reduction catalyst (LBO and LDO series) and LBO-A additive; propylene maximizing catalyst (LCC-1) and additive LCC-A; heavy oil conversion FCC catalyst LHO-1 and LB series; high octane number FCC catalyst (LOG and LDC series). When LBO-12 catalyst reach $66 \%$ of the system inventory, the gasoline olefin yield decreases $9.1 \%$; When LBO- 16 catalyst reach $50 \%$ of the system inventory, the gasoline olefin yield decreases by $10 \%$; LBO-16 catalyst's application shows that the diesel yield maintains the same. When LBO-A reaches $15 \%$ of system inventory, the gasoline RON has increased by 0.6 units and gasoline olefin yield decreased by $3.3 \%$. The standardization on LDO-75 catalyst after its system inventory reaches $80 \%$ shows that the light oil yield and total liquid yield have increased 1.37 and $0.54 \%$, respectively; After adopting LCC-2 catalyst and compared to $0 \%$ case scenario, the propylene yield increases by $1.01 \%$. When LCC-A reaches $6 \%$ of system inventory, the propylene yield increases by $1.41 \%$ and RON by 1.5 units; the total liquid yield increases by $1.44 \%$ and slurry yield drops by $1.41 \%$ after LHO- 1 catalyst reaches $80 \%$ of system inventory; LDC-200 catalyst's application shows $1.77 \%$ total liquid yield increase, $0.83 \%$ light oil yield increase and $1.72 \%$ increase on propylene selectivity. The gasoline RON also increases 1.5 units; by adopting TMP technology and its matching catalyst LCC-300, propylene yield in product distribution reached as high as
\end{abstract}

Zhaoyong Liu

1zy0539@126.com

1 State Key Lab of Heavy Oil Processing, China University of Petroleum, Qingdao 266555, Shandong, China

2 Lanzhou Petrochemical Research Institute, CNPC, Lanzhou 730060, Gansu, China
$20.38 \%$; When MIP process matching catalyst LIP-100's system inventory reached $100 \%$, LPG's yield increased by $1.04 \%$, gasoline yield increased by $0.74 \%$; The comparison of results between end-term and blank case standardization of MIP-CGP process matching catalyst LDR-100 shows $0.4 \mathrm{wt} \%$ increase in diesel yield, $3.52 \mathrm{wt} \%$ increase in LPG yield and 1.3 units on gasoline RON.

Keywords Catalytic cracking - Catalyst - Additives . Gasoline olefin · Propylene - Heavy oil conversion · Matching technologies

\section{Introduction}

With the rapid development of global economy, refining technology is developing towards the direction of heavy oil's conversion to light products, clean gasoline production and maximizing low carbon olefin. Aiming to this direction of development, Lanzhou Petrochemical Research Institute, CNPC has developed olefin reduction catalysts and additives, propylene maximizing catalysts and additives, FCC heavy oil conversion catalysts, high octane number catalysts and special processes' matching catalysts. This article mainly states the research on the series FCC catalysts' industrial application.

\section{Industrial application of Olefin Reduction Catalysts and additives}

\section{(1)LBO-16}

There are different ways to reduce gasoline olefin and adopting olefin reduction catalyst is the most direct and 
Table 1 Industrial application of olefin reduction catalysts

\begin{tabular}{lllll}
\hline Item & $\begin{array}{l}\text { Base } \\
\text { catalyst }\end{array}$ & $\begin{array}{l}\text { LBO- } \\
12\end{array}$ & $\begin{array}{l}\text { Base } \\
\text { catalyst }\end{array}$ & $\begin{array}{c}\text { LBO- } \\
16\end{array}$ \\
Feedstock & Kuxi VGO and VR & Daqing AR and VR \\
\hline Feed rate/t h ${ }^{-1}$ & 54.12 & 50.97 & 122.0 & 121.8 \\
Blending rate, wt\% & 14.14 & 14.13 & 5.05 & 1.16 \\
Rx temperature/ ${ }^{\circ} \mathrm{C}$ & 501 & 498 & 487 & 482 \\
Product/wt\% & & & & \\
Dry gas & 4.82 & 4.60 & 3.90 & 3.80 \\
LPG & 9.12 & 10.10 & 11.88 & 10.93 \\
Gasoline & 43.65 & 45.20 & 42.07 & 42.72 \\
Diesel & 30.24 & 28.40 & 31.80 & 31.87 \\
Slurry & 4.18 & 3.50 & 2.99 & 2.84 \\
Coke & 7.17 & 7.42 & 7.06 & 7.44 \\
Loss & 0.82 & 0.78 & 0.30 & 0.40 \\
Light oil yield/\% & 73.89 & 73.60 & 73.87 & 74.59 \\
Olefin content of & 46.5 & 37.4 & 46.3 & 36.3 \\
gasoline/\% & & & & \\
Gasoline MON & & 79.80 & 79.2 & 78.9 \\
Gasoline RON & & 92.12 & 90.2 & 89.2 \\
\hline
\end{tabular}

economic way [1]. The research has put forward a new reaction mode [2] to reduce FCC gasoline's olefin content. A modification technology which mainly contains high rare earth content stable y zeolite, rare earth ultra-stable $\mathrm{Y}$ zeolite and other multiple active components is developed. LBO-12, LBO-16 olefin reduction catalysts and LBO-A additive are developed. LBO-16 is the modified secondgeneration diesel maximizing olefin reduction catalyst improved on the basis of LBO-12.

\section{Olefin reduction catalysts}

LBO-12 and LBO-16 catalysts are applied in Lanzhou Petrochemical Company's 0.15 Mt/a FCC unit [3] and Harbin Petrochemical Company's 1.2 Mt/a RFCC unit, respectively [4]. The systematic inventories of the two FCC units are 66 and $50 \%$, respectively, and the results are shown in Table 1.

From Table 1 we can see that when LBO-12 catalyst reaches $66 \%$ of the system inventory, the unit's LPG and gasoline yields increase while diesel yield and light oil yield slightly decrease. The slurry weight yield dropped $0.68 \%$ and gasoline olefin yield decreases by $9.1 \%$. LBO12 catalyst exhibits relatively strong heavy oil cracking and olefin reduction abilities; when LBO-12 catalyst reaches $50 \%$ of the system inventory and compares to blank case, the LPG yield decreased by $0.95 \%$, gasoline and light oil yield increased by 0.65 and $0.72 \%$, respectively, while diesel yield basically maintained the same. This has proved the LBO-16 catalyst could moderately prevent intermediate
Table 2 Industrial application of olefin reduction additive

\begin{tabular}{lll}
\hline Item & Base catalyst & $\begin{array}{l}\text { Base catalyst + LBO- } \\
\text { A }\end{array}$ \\
Feedstock & Daqing AR and VR & Daqing AR and VR \\
\hline Feed rate/t $\mathrm{h}^{-1}$ & 120.7 & 120.2 \\
Rx temperature/ ${ }^{\circ} \mathrm{C}$ & 482 & 486 \\
Product distribution/ & & \\
$\%$ & & \\
Dry gas & & 11.99 \\
LPG & 11.59 & 40.69 \\
Gasoline & 40.89 & 27.77 \\
Diesel & 27.67 & \\
Slurry & & 7.40 \\
Coke & 7.35 & \\
Loss & & 73.40 \\
Light oil yield/\% & 73.67 & \\
PIONA/\% & & 9.6 \\
Aromatics & 8.6 & 33.5 \\
Olefin & 36.8 & 56.9 \\
Paraffin & 54.6 & 79.4 \\
MON & 79.2 & 88.0 \\
RON & 87.4 & \\
\hline
\end{tabular}

products from over cracking and it is positive to preserve light oil fractions.

\section{$L B O-A$}

Table 2 shows the data after applying LBO-A additive to Harbin Petrochemical Company's 1.2 Mt/a RFCC unit. Comparing to blank case, when LBO-A's system inventory is $15 \%$, under the premises of no obvious change to products' yield, the gasoline RON has increased by 0.6 units and gasoline olefin reduced by $3.3 \%$. This proves LBO-A's strong olefin reduction and octane number boosting abilities [5].

\section{LDO-70 and LDO-75 catalysts}

LDO series catalysts have adopted innovative high activity and stability zeolite's modification technology, active porous matrix material, heavy metal trapping technology and ZSM-5 zeolite's modification technology.

Dushanzi Petrochemical Company's I FCC Unit is a high-low parataxis riser wax oil FCC Unit with processing capacity of $0.8 \mathrm{Mt} / \mathrm{a}$. Its feedstock is mainly the mix of atmospheric tower fraction, vacuum tower fraction and coking fraction. The standardization was conducted when LDO-75 reached $80 \%$ of the system inventory. After adopting LDO-75, the dry gas, LPG and gasoline yields have decreased by $0.49,0.64$ and $2.13 \%$, respectively; diesel 
yield has increased by $3.48 \%$ while slurry and coke yield decreased by 0.17 and $0.06 \%$; light oil yield and total liquid yield, respectively, increased by 1.37 and $0.54 \%$ [6].

\section{Application of propylene maximizing catalysts and additives}

Propylene is mainly produced by steam cracking and catalytic cracking. The primary choice to maximizing propylene production in China is still catalytic cracking process. Therefore, propylene maximizing additive LCC-A and catalyst LCC-1 were developed by Lanzhou Petrochemical Research Institute.

\section{Propylene maximizing additive}

Dalian Petrochemical Company started using LCC-A additive in 2004. Its feedstock mainly comes from Daqing and mixed with $8 \%$ Russian Crude Oil. When LCC-A reached $6 \%$ of the system inventory and compared to blank case, LPG's yield has increased with no effects on dry gas yield and total liquid yield. The coke selectivity remained basically the same and under the condition of not effecting gasoline olefin yield, RON has increased by more than 1.5 units.

According to industrial data on propylene yield from January to June in 2004, with the addition of LCC-A, propylene's yield has increased gradually. The propylene yield in LPG has reached $6.40 \%$ and increased by $1.41 \%$.

\section{Propylene maximizing catalyst}

LCC-2 is a new type of propylene maximizing catalyst developed by Lanzhou Petrochemical Company and it has adopted several self-innovated patent technology as follows: (1) new matrix material technology. It not only has good heavy oil conversion and heavy metal resistance ability, but is also positive to form ideal pores for propylene molecules to diffuse; (2) active component's modification technology has improved its hydrothermal and acidity stability. The high cracking activity to light olefin is maintained to achieve the goals of reducing gasoline olefin and maximizing propylene; (3) Y zeolite's modification technology has reduced gasoline olefin yield through controlling acid center's distribution. Table 3 shows the industrial application results of LCC-2 catalyst in Daqing refining Company, CNPC's $1.80 \mathrm{Mt} / \mathrm{a}$ ARGG FCC unit. The unit's reactor-regenerator system is of high-low parallel arrangement. The feedstock mainly consisted of atmospheric tower resid oil, vacuum tower resid and wax oil. The unit's products are LPG with rich propylene and high octane number gasoline. Comparing to blank case, the unit's dry gas, LPG and gasoline yield have increased by
Table 3 Industrial application experiment on LCC-2 catalyst

\begin{tabular}{lcc}
\hline Item & LCC-2catalyst & Base catalyst \\
\hline Product distribution/\% & & \\
Dry gas & 4.79 & 4.55 \\
LPG & 25.55 & 25.11 \\
Gasoline & 40.84 & 40.34 \\
LCO & 6.84 & 15.70 \\
HCO & 9.46 & 2.39 \\
Coke & 8.56 & 8.19 \\
Slurry & 3.58 & 3.05 \\
Loss & 0.39 & 0.40 \\
Total liquid oil yield/\% & 82.68 & 83.81 \\
Propylene & 8.84 & 7.83 \\
\hline
\end{tabular}

$0.24,0.44$ and $0.5 \%$, respectively; diesel yield has decreased by $1.79 \%$ and propylene yield increased by $1.01 \%$ [7].

\section{Industrial applications of heavy oil conversion FCC catalysts}

With the increasing heavy oil's proportion in feedstock, ordinary olefin reduction catalyst's olefin reduction ability is severely constrained and light oil yield is decreased. Besides, there are large quantities of heavy metals like $\mathrm{Ni}$, $\mathrm{V}$ and $\mathrm{Fe}$ in the feedstock. These heavy metals are harmful to structure stability of zeolite's active center and declined active center's accessibility. Therefore, Lanzhou Petrochemical Company developed new type of heavy oil conversion FCC catalyst LHO-1 and LB series which obtains olefin reduction function.

Table 4 shows when the LHO-1 catalyst's proportion increases in system inventory, the $\mathrm{V}$ and $\mathrm{Ca}$ poisoning level on e-cat is increasing and V's yield has increased as much as $1267 \times 10^{-6}$. The light oil yield and total liquid yield also increased while slurry yield decreased. When LHO-1 took up $80 \%$ of the system inventory, the total liquid yield has increased by $1.44 \%$ compared to the case in which no LHO- 1 is added and the slurry yield decreased by $1.41 \%$. After using LHO-1 catalyst, the gasoline octane number is basically stable as gasoline olefin yield dropped. The results proved that LHO-1 catalyst has good heavy oil cracking ability, good heavy metal resistance and olefin reduction ability.

\section{LB series catalyst}

With Kaolin-clay in situ technology, Lanzhou Petrochemical Company developed LB-1, LB-2, LB-3 and LB-5 series Kaolin-clay catalysts in succession. LB series catalysts have superior heavy oil cracking ability, good heavy metal resistance and good attrition resistance. 
Table 4 Industrial application of heavy oil conversion catalyst

\begin{tabular}{lllll}
\hline LHO-1 proportion in inventory/\% & 0 & 30 & 50 & 80 \\
\hline Blending rate & 40.92 & 41.24 & 40.5 & 39.27 \\
Heavy metal, $\mu \mathrm{g} / \mathrm{g}$ & & & & \\
$\mathrm{V}$ & 8489 & 8549 & 9607 & 9756 \\
$\mathrm{Ca}$ & 2412 & 3415 & 3901 & 3071 \\
Product distribution/\% & & & & \\
Dry gas & 3.66 & 3.74 & 3.76 & 3.75 \\
LPG & 12.56 & 12.02 & 12.41 & 13.03 \\
Gasoline & 42.05 & 43.31 & 43.60 & 43.27 \\
Diesel & 24.59 & 24.63 & 24.37 & 24.34 \\
Slurry & 8.16 & 7.30 & 6.87 & 6.75 \\
Coke & 8.48 & 8.51 & 8.50 & 8.37 \\
Loss & 0.50 & 0.49 & 0.49 & 0.49 \\
Light oil yield/\% & 66.64 & 67.94 & 67.97 & 67.61 \\
Total liquid oil yield/\% & 79.20 & 79.96 & 80.38 & 80.64 \\
Olefin content of gasoline/\% & 44.1 & & 42.30 & \\
MON & 82.25 & & 82.19 & \\
RON & 90.4 & & 90.5 & \\
\hline
\end{tabular}

Table 5 Catalyst's industrial application experiment

\begin{tabular}{lcc}
\hline Item & LDO-75 catalyst & Base catalyst \\
\hline Product distribution/\% & & \\
$\quad$ Dry gas and loss & 1.43 & 1.92 \\
LPG & 11.66 & 12.30 \\
Gasoline & 53.35 & 55.48 \\
Diesel & 22.53 & 19.05 \\
Slurry & 5.66 & 5.83 \\
Coke & 5.36 & 5.42 \\
Light oil yield/\% & 75.90 & 74.53 \\
Total liquid oil yield/\% & 93.21 & 92.67 \\
\hline
\end{tabular}

In Tables 5 and 6, when LB-5 catalyst is applied to Lanzhou Petrochemical Company's 0.4Mt/a FCC unit and compared to blank case, the product slate after adopting LB-5 is optimized. The dry gas yield decreases by $1.37 \%$, slurry yield decreases by $0.21 \%$; coke yield decreases while light oil yield increases by $0.83 \%$ and total liquid yield increases by $1.79 \%$. This result proves LB-5 catalyst has strong heavy oil cracking ability and ideal product distribution.

\section{Catalyst for producing gasoline with high octane number}

With the stricter requirements on gasoline specifications according to environmental law and refineries' matching gasoline hydro treating and etherification units'
Table 6 LB-5 catalyst's industrial application experiment

\begin{tabular}{lcc}
\hline Item & LB-5 catalyst & Base catalyst \\
\hline Product distribution/\% & & \\
$\quad$ Dry gas & 3.45 & 4.82 \\
LPG & 10.08 & 9.12 \\
Gasoline & 44.46 & 43.65 \\
Diesel & 30.26 & 30.24 \\
Slurry & 3.97 & 4.18 \\
Coke & 6.94 & 7.17 \\
Light oil yield/\% & 74.72 & 73.89 \\
Total liquid oil yield/\% & 84.80 & 83.01 \\
Conversion/\% & 65.77 & 65.58 \\
\hline
\end{tabular}

Table 7 LDC-200 catalyst's industrial application experiment

\begin{tabular}{lcc}
\hline Item & LDC-200 catalyst & Base catalyst \\
\hline Product distribution/\% & & \\
$\quad$ Dry gas & 3.66 & 3.68 \\
LPG & 14.40 & 13.47 \\
Gasoline & 46.95 & 46.66 \\
Diesel & 22.22 & 21.68 \\
Slurry & 4.15 & 4.86 \\
Coke & 8.62 & 9.65 \\
Light oil yield/\% & 69.17 & 68.34 \\
Total liquid oil yield/\% & 83.57 & 81.80 \\
Olefin content of gasoline/\% & 42.4 & 37.5 \\
RON & 92.3 & 90.8 \\
\hline
\end{tabular}

completion, the gasoline's processing method is significantly changed. FCC gasoline is cut and then light gasoline is sent to etherification units to produce etherified gasoline; heavy gasoline is sent to hydro-treating units to produce gasoline rich in $\mathrm{C} 5$ and $\mathrm{C} 6$ olefins and the sulfur content in FCC gasoline is further decreased. According to the changing demands of oil product's market and heavier and more inferior feedstock, Petrochemical Research Institute, CNPC, has successfully developed LOG-91, LOG-91, LDC-100 and LDC-200 FCC catalysts. LDC-200 catalyst adopts high-dispersion, high-stability $\mathrm{Y}$ zeolite and selective zeolite as active components and is prepared by "heavy metal resistance" technology, active components cracking technology and catalyst pore construction and assembling technology. It has advantages of strong heavy oil conversion ability, low coke yield, improving gasoline octane number and flexible gasoline olefin adjustments.

LDC-200 catalyst is successfully applied on Lanzhou Petrochemical Company's $3 \mathrm{Mt} / \mathrm{a}$ RFCC unit. The unit mainly processes Xinjiang VGO and VR. The designed mixing refining proportion is $50 \%$. Table 7 shows that 
after adopting LDC-200 catalyst, gasoline yield has increased by $0.29 \%$; diesel yield has increased by $0.54 \%$; slurry yield has decreased by $0.29 \%$ and coke yield and loss have decreased by $1.03 \%$. The total liquid yield has increased by $1.77 \%$; light oil yield increased by $0.83 \%$; Propylene selectivity increased by $1.72 \%$; gasoline olefin increased by 4.9 vol\% and gasoline RON increased by 1.5 units. LDC-200 catalyst's heavy oil conversion ability and coke selectivity are better than base catalyst. The product distribution and properties are apparently improved and have satisfied 3Mt/a RFCC unit's technical requirements.

\section{Special process matching catalyst}

\section{TMP special catalysts}

Two-stage riser catalytic cracking technology is an innovative FCC technology developed by China University of petroleum. The core idea of this technology is stage by stage reaction, catalyst relay, short reaction and big cat to oil mass ratio. Chunyi Li [8] has put forward the technical route of propylene maximizing using two-stage riser's catalytic cracking process while giving consideration to gasoline and diesel's production (TMP). Petrochemical Research Institute, CNPC, has developed LCC-300 twostage catalyst for propylene maximizing after deep analysis on TMP technology.

LCC-300 catalyst has been applied on Daqing refinery's $0.12 \mathrm{Mt} / \mathrm{a}$ TMP unit. The first-stage riser's feedstock is the mixture of mixing $\mathrm{C} 4$ and Daqing atmospheric tower resid oil; the second-stage riser is mixture of recycle light gasoline, recycle oil and recycle slurry. Table 8 shows that after adopting TMP technology and matching catalyst LCC-300, the intermediate product propylene's yield has reached $20.38 \%$; total liquid yield is $82.95 \%$ and the sum of dry gas and coke is $13.99 \%$. This has proved the

Table 8 LCC-300 catalyst's industrial application experiment

\begin{tabular}{lc}
\hline Item & LCC-300 catalyst \\
\hline Product distribution/\% & \\
Dry gas & 5.19 \\
LPG & 37.34 \\
Gasoline & 28.82 \\
Diesel & 16.79 \\
Slurry & 2.56 \\
Coke & 8.8 \\
Light oil yield/\% & 45.61 \\
Total liquid oil yield/\% & 82.95 \\
Propylene/\% & 20.38 \\
\hline
\end{tabular}

advantage of LCC-300 catalyst on propylene maximizing and dry gas and coke yields' reducing.

\section{MIP and MIP-CGP special catalysts}

Petrochemical Research Institute has successfully developed maximizing isoparaffin technology and clean gasoline component production and propylene maximizing FCC technology and these technologies have been successfully industrial applied in several domestic units. To match MIP and MIP-CGP process [9], LIP-100, LIP-200B, LIP-300 and LDR-100 catalysts are developed in succession. MIP process adopts series riser reactors. The series riser reactor is divided into to reaction zones. The first cracking reaction mainly takes place in the first reacting zone. Hydrogen transfer reaction and isomerization reactions take place in the second reacting zone to suppress second cracking reaction. By using low reacting temperature and relatively long reaction time, olefins are transferred to isoparaffin and aromatics. MIP-CGP process is developed on the basis of MIP process. The difference is that the temperature of first reacting zone is high, the contact time between feedstock and catalyst is short, the cat to oil ratio is high and the active components' acidity is better than ordinary zeolites; therefore, the feedstock's big molecule alkane's unimolecule cracking reaction is enforced and then the goal of olefin maximizing can be achieved. The second reaction zone has lower reacting temperature, longer reaction time and higher acidity density of active components (positive for double molecule cracking and hydrogen transfer) which could realize the double molecule cracking reaction of the rest of the feedstock's large molecule paraffins and brings down dry gas yield. What is more important is that the hydrogen transfer reaction and continuous gasoline olefin cracking reactions are enforced to the largest extent to realize the goals of gasoline olefin reduction and propylene maximizing.

LIP-100 catalyst has adopted ultra-stable Y zeolite and ZSM-5 zeolite as active components and NPM compound alumina porous matrix's complex modification technology. At the same time, special high-temperature alumina supporter component is prepared.

Table 9 shows that when LIP-100 catalyst is applied in Jinxi Petrochemical Company's 1.8Mt/a MIP FCC unit and when the its inventory reaches $100 \%$, the dry gas yield decreased by $0.33 \%$; LPG yield increased by $1.04 \%$; gasoline percentile increased by $0.74 \%$; diesel, slurry and coke's yields have decreased by $0.88,0.47$ and $0.20 \%$, respectively; light oil yield decreased by $0.14 \%$; total liquid yield increased by $0.90 \%$ and propylene yield increased by $1.28 \%$. Generally speaking, the LIP series catalyst has good heavy oil conversion ability. At the same time, dry gas and coke yields have decreased. The catalytic 
Table 9 LIP-100 catalyst's industrial application experiment

\begin{tabular}{lcc}
\hline Item & LIP-100 catalyst & Base catalyst \\
\hline Product distribution/\% & & \\
$\quad$ Dry gas & 3.30 & 3.63 \\
LPG & 13.25 & 12.21 \\
Gasoline & 45.95 & 45.21 \\
Diesel & 27.05 & 27.93 \\
Slurry & 2.35 & 2.82 \\
Coke & 7.60 & 7.80 \\
Light oil yield/\% & 73.00 & 73.14 \\
Total liquid oil yield/\% & 86.25 & 85.35 \\
Propylene/\% & 5.15 & 3.87 \\
\hline
\end{tabular}

Table 10 LDR-100 catalyst's industrial application experiment

\begin{tabular}{lcc}
\hline Item & LIP-100 catalyst & Base catalyst \\
\hline Product distribution/\% & & \\
$\quad$ Dry gas & 4.07 & 4.45 \\
LPG & 17.86 & 14.34 \\
Gasoline & 43.22 & 45.51 \\
Diesel & 23.12 & 22.72 \\
Slurry & 4.58 & 5.25 \\
Coke & 6.86 & 7.44 \\
Light oil yield/\% & 66.34 & 68.23 \\
Total liquid oil yield/\% & 84.20 & 82.57 \\
Propylene/\% & 6.0 & 5.8 \\
RON & 91.1 & 89.8 \\
\hline
\end{tabular}

cracking reaction is enforced and thermal cracking reaction is lessened [10].

LDR-100 catalyst adopts active component with high acidity density and high acidity density zeolite's compound technology. Through adjustments on acidity, propylene's yield is maximized while giving consideration to gasoline olefin reduction. The LDR-100 catalyst is applied in Harbin Petrochemical Company, CNPC's $0.6 \mathrm{Mt} / \mathrm{a}$ MIP-CGP RFCC unit. Table 10 shows the product distribution comparison between LDR-100's end-term standardization and blank case standardization: the diesel yield has increased by $0.40 \mathrm{wt} \%$; the LPG's yield has increased by $3.52 \mathrm{wt} \%$; the dry gas yield has decreased by $0.38 \mathrm{wt} \%$; the slurry's yield has decreased by $0.67 \mathrm{wt} \%$; the coke yield has decreased by $0.58 \mathrm{wt} \%$; the conversion rate has increased by $0.26 \mathrm{wt} \%$; the total liquid yield has increased by $1.63 \mathrm{wt} \%$ and the gasoline RON has increased 1.3 units. To sum up, LDR-100 catalyst has good heavy oil conver- sion ability in industrial application and it has advantages of effectively bringing down dry gas and coke yields, increasing target products' yields, increasing total liquid yield and effectively improving gasoline octane number.

\section{Conclusions}

When LBO-12 and LBO-16 Catalysts reach 66 and $50 \%$ of system inventory, respectively, the gasoline olefin yield has decreased by 9.1 and $10 \%$, respectively. LBO-16 catalyst's application shows that the diesel yield stays the same. When LBO-A reaches $15 \%$ of system inventory, the gasoline RON has increased by 0.6 units and gasoline olefin yield decreased by $3.3 \%$.

When conducting summary standardization on LDO-75 catalyst after its system inventory reaches $80 \%$, the result shows that the light oil yield and total liquid yield have increased by 1.37 and $0.54 \%$, respectively.

After adopting LCC-2 catalyst and compared to $0 \%$ case scenario, the propylene yield increases by $1.01 \%$. When LCC-A reaches $6 \%$ of system inventory, the propylene yield increases by $1.41 \%$ and RON by 1.5 units.

After LHO-1 takes $80 \%$ of system inventory, the total liquid yield increases by $1.44 \%$ and slurry yield drops by $1.41 \%$.

LDC-200 catalyst's application shows $1.77 \%$ total liquid yield increase, $0.83 \%$ light oil yield increase and $1.72 \%$ increase on propylene selectivity. The gasoline RON also increases by 1.5 units.

By adopting TMP technology and its matching catalyst LCC-300, propylene yield in product distribution reached as high as $20.38 \%$.

When MIP process matching catalyst LIP-100's system inventory reached $100 \%$, LPG's yield increased by $1.04 \%$, gasoline yield increased by $0.74 \%$.

The comparison of results between end-term and blank case standardization of MIP-CGP process matching catalyst LDR-100 shows $0.4 \mathrm{wt} \%$ increase in diesel yield, $3.52 \mathrm{wt} \%$ increase in LPG yield and 1.3 units on gasoline RON.

To sum up, research and development of new type of FCC catalyst for better heavy oil conversion is imperative. As we all know, heavy oil with large molecules and highlevel content of resistance metal is difficult to crack and easy to produce coke.

Research and development of new type of catalyst for heavy oil conversion is imperative. Heavy oil has a series of characteristics, such as lager molecules, not easy to crack, high content of heavy metal, and so on. So based on these, new type of catalyst should have the following functions: 
1. A new type of macroporous active material is used as the matrix to improve the heavy oil cracking capability of the catalyst;

2. using of innovative matrix preparation technology to increase pore structure, especially pore volume, and not effect on the attrition of catalyst;

3. using the unique molecular sieve modification technology to enhance heave metal resistance ability, and also improve the activity and thermal stability of catalyst;

4. $\mathrm{R} \& \mathrm{D}$ of new catalyst to adapt to new FCC technology, such as circulating regenerated catalyst (CRC), maximum $\mathrm{C} 4$ olefin, and so on.

Acknowledgments The authors thank the Ministry of Science and Technology Management of PetroChina and National Natural Science Foundation of China (No. 21476263) for providing financial support.

Open Access This article is distributed under the terms of the Creative Commons Attribution 4.0 International License (http:// creativecommons.org/licenses/by/4.0/), which permits unrestricted use, distribution, and reproduction in any medium, provided you give appropriate credit to the original author(s) and the source, provide a link to the Creative Commons license, and indicate if changes were made.

\section{References}

1. Conghua L, Yusheng G, Xionghou G, Yundong L (2004) Advances in technology of naphtha olefin reducing FCC catalyst [J]. Petrochem Technol Appl 22(4):244-248
2. Liu C, Gao X, Zhang Z (2004) Surface modification of zeolite Y and mechanism for reducing naphtha olefin formation in catalytic cracking reaction [J]. Appl Catal A 264:225-228

3. Jiang D, Ailing Y, Qing Y, Fang Z (2003) Commercial application of a gasoline olefin reduction catalyst LBO-12 in FCCU [J]. Petrol Process Petrochem 34(3):5-9

4. Zhenjiang Z (2003) Commercial application of olefin reduction LBO-16 catalyst [J]. Petrochem Technol Appl 21(4):267-269

5. Hongbin Z (2004) Application of high-octane olefin reduction catalyst LBO-A in FCCU [J]. Petrochem Technol Appl 22(2):119-121

6. Liang Z, Xubiao Z, Song Q, Kan X (2011) Commercial application of LDO-75 FCC catalyst processing heavy feedstocks [J]. Petrol Process Petrochem 42(10):35-38

7. Jiajun T, Longqing W, Feng L (2008) Application of maximizing propylene catalyst LCC-2 in fluidized-bed catalytic cracking unit for heavy oil [J]. Petrochem Technol Appl 26(4):336-339

8. Zhaoyong 1, Zhongdong Z, Xionghou G, Haitao Z (2011) Industrial application of LCC-300 catalyst for enhancing propylene yield in two-stage riser catalytic pyrolysis of heavy oil [J]. Petrol Process Petrochem 42(9):47-50

9. Wendong H, Rukui H, Jianhong G (2006) Commercial application of new FCC process-MIP-CGP [J]. Pet Refin Eng 36(9): $1-4$

10. Wenting W, Da M (2006) Commercial application of LIP-100 catalyst in RFCC unit $[\mathrm{J}]$. China Foreign Energy 11(6):61-65 